\title{
Decreased Nicotinic Receptor Availability in Smokers with Slow Rates of Nicotine Metabolism
}

\author{
Jacob G. Dubroff ${ }^{1}$, Robert K. Doot ${ }^{1}$, Mary Falcone ${ }^{2}$, Robert A. Schnoll ${ }^{2}$, Riju Ray ${ }^{3}$, Rachel F. Tyndale ${ }^{4}$, \\ Arthur L. Brody ${ }^{5,6}$, Catherine Hou ${ }^{1}$, Alexander Schmitz ${ }^{1}$, and Caryn Lerman ${ }^{2}$ \\ ${ }^{1}$ Department of Radiology, University of Pennsylvania, Philadelphia, Pennsylvania; ${ }^{2}$ Department of Psychiatry, University \\ of Pennsylvania, Philadelphia, Pennsylvania; ${ }^{3}$ Global Medical Affairs, GlaxoSmithKline, Brussels, Belgium; ${ }^{4}$ Department \\ of Pharmacology and Toxicology, and Department of Psychiatry, CAMH, University of Toronto, Toronto, Canada; ${ }^{5}$ Department of \\ Psychiatry and Biobehavioral Sciences, University of California, Los Angeles, California; and ${ }^{6}$ Department of Psychiatry, Veterans \\ Administration Greater Los Angeles Healthcare System, Los Angeles, California
}

The nicotine metabolite ratio (NMR), a stable measure of hepatic nicotine metabolism via the CYP2A6 pathway and total nicotine clearance, is a predictive biomarker of response to nicotine replacement therapy, with increased quit rates in slower metabolizers. Nicotine binds directly to nicotinic acetylcholine receptors (nAChRs) to exert its psychoactive effects. This study examined the relationship between NMR and nAChR ( $\alpha 4 \beta 2^{*}$ subtype) availability using PET imaging of the radiotracer $2-18 \mathrm{~F}-$ fluoro-3-(2(S)-azetidinylmethoxy)pyridine $(2-18 \mathrm{~F}-\mathrm{FA}-$ 85380 , or $\left.2-{ }^{18} \mathrm{~F}-\mathrm{FA}\right)$. Methods: Twenty-four smokers-12 slow metabolizers (NMR $<0.26$ ) and 12 normal metabolizers (NMR $\geq$ 0.26 ) - underwent $2-{ }^{18}$ F-FA-PET brain imaging after overnight nicotine abstinence ( $18 \mathrm{~h}$ before scanning), using a validated bolus-plusinfusion protocol. Availability of nAChRs was compared between NMR groups in a priori volumes of interest, with total distribution volume $\left(V_{T} / f_{P}\right)$ being the measure of $n A C h R$ availability. Cravings to smoke were assessed before and after the scans. Results: Thalamic nAChR a4ß2* availability was significantly reduced in slow nicotine metabolizers $(P=0.04)$. Slow metabolizers exhibited greater reductions in cravings after scanning than normal metabolizers; however, craving was unrelated to $\mathrm{nAChR}$ availability. Conclusion: The rate of nicotine metabolism is associated with thalamic nAChR availability. Additional studies could examine whether altered $n A C h R$ availability underlies the differences in treatment response between slow and normal metabolizers of nicotine.

Key Words: PET; nicotine; addiction; $2-{ }^{18} \mathrm{~F}-\mathrm{FA}-85380$; nicotine metabolite ratio; $\alpha 4 \beta 2^{*}$ nAChR

J Nucl Med 2015; 56:1724-1729

DOI: 10.2967/jnumed.115.155002

A n estimated 43.8 million Americans and 1.1 billion people worldwide smoke cigarettes $(1,2)$. Tobacco use is the leading cause of preventable death, representing a significant medical and public health problem (3). Despite the burden of nicotine

Received Feb. 3, 2015; revision accepted Jul. 14, 2015.

For correspondence or reprints contact: Jacob G. Dubroff, Hospital of the University of Pennsylvania, Department of Radiology, Division of Nuclear Medicine and Clinical Molecular Imaging, 3400 Spruce St., 110 Donner Bldg., Philadelphia, PA 19104.

E-mail: jacob.dubroff@uphs.upenn.edu

Published online Aug. 13, 2015.

COPYRIGHT (C 2015 by the Society of Nuclear Medicine and Molecular Imaging, Inc. dependence on public health, available pharmacotherapies have long-term failure rates of $70 \%-80 \%$ (4).

Individual differences in rate of nicotine metabolism via CYP2A6 have been linked to variation in smoking rates (i.e., cigarettes per day) $(5,6)$. The ratio of $3^{\prime}$-hydroxycotinine to cotinine, referred to as the nicotine metabolite ratio (NMR), has been validated as a measure of inherited differences in hepatic metabolism of nicotine and as a predictor of both total nicotine clearance and response to smoking cessation therapies $(7,8)$. Smokers who are normal metabolizers of nicotine are less likely to quit smoking with transdermal nicotine than slow metabolizers $(7,9)$. A recent multicenter, randomized, placebocontrolled trial of 1,246 smokers showed that varenicline was more efficacious than the nicotine patch in normal metabolizers as measured by NMR; however, in slow metabolizers, these treatments had equivalent efficacy (10). Among pregnant women, who clear nicotine at higher rates than nonpregnant women, those with a higher NMR were also less likely to achieve cessation (11). Despite the validated clinical significance of the NMR for targeting smoking cessation therapy, the mechanisms underlying its association with treatment response are unknown. This study examined whether slow and normal metabolizers differ in nAChR availability after approximately $18 \mathrm{~h}$ of abstinence from nicotine. We focused on short-term abstinence because ability to refrain from nicotine during the first day of an attempt to quit is highly predictive of long-term abstinence $(12,13)$.

Chronic nicotine exposure in both animal models and humans has been shown to increase nAChR density, based on immunohistochemistry and other in vitro molecular probes specific for the nAChR $\alpha 4 \beta 2 *$ subtype (14-18). PET imaging and SPECT using $2-{ }^{18} \mathrm{~F}$-fluoro-3-(2 $(S)$-azetidinylmethoxy)pyridine (2-18 F-FA-85380, or $\left.{ }^{2-}{ }^{18} \mathrm{~F}-\mathrm{FA}\right)$ and ${ }^{123}$ I-5-IA, respectively, have confirmed these results in vivo in humans (19-21). Specifically, chronic nicotine exposure leads to nAChR upregulation (22), whereas quitting smoking leads to decreased receptor levels (i.e., normalization) (23). SPECT molecular imaging studies of the nAChR $\alpha 4 \beta 2 *$ subtype have also shown that $\mathrm{nAChR}$ availability in smokers peaks after 1 wk of abstinence $(22,24)$, suggesting the persistent occupation of nAChRs by nicotine. These studies have consistently shown the highest density of nAChRs ( $\alpha 4 \beta 2 *$ subtype) to be in the thalamus (21). Studies have also shown that smoking, exposure to secondhand smoke, and administration of the smoking cessation medication varenicline displaces $2-{ }^{18} \mathrm{~F}-\mathrm{FA}$ and ${ }^{123} \mathrm{I}-5$-IA binding to the $\alpha 4 \beta 2 *$ receptor subtype $(25-28)$. On the basis of these data, we hypothesized that slow nicotine metabolizers would have lower $\mathrm{nAChR}$ availability after overnight nicotine abstinence than normal 
metabolizers. Changes in $\mathrm{nAChR}$ availability have been observed in the thalamus and cortex $(25,26,29)$, and for that reason our a priori analysis targeted the thalamus, frontal cortex, temporal cortex, and whole brain.

\section{MATERIALS AND METHODS}

\section{Participants}

This study was conducted in accordance with the Declaration of Helsinki, and the University of Pennsylvania Institutional Review Board approved all procedures. Individuals who expressed interest in participating in smoking cessation research at the University of Pennsylvania completed an in-person intake session during which they provided written informed consent and were screened for eligibility. Eligible participants were between the ages of 18-65 y and reported smoking at least 10 cigarettes per day for the past 6 mo (confirmed by an exhaled carbon monoxide $[\mathrm{CO}]$ reading greater than 10 parts per million [ppm]) and were fluent English speakers. Persons with a history of DSM Axis I psychiatric or substance disorders (except nicotine dependence), assessed using the Mini International Neuropsychiatric Interview (30), and those taking psychotropic medications were excluded. Other exclusion criteria included current use of chewing tobacco, snuff, or smoking cessation products; pregnancy, planned pregnancy, or breastfeeding; history of brain injury; or MR imaging-contraindicated material in the body.

The NMR was determined from a plasma sample provided at intake (6). Participants were classified as slow metabolizers (NMR $<0.26$ ) or normal metabolizers ( $\mathrm{NMR} \geq 0.26$ ), based on prior clinical data showing differences in smoking cessation outcomes using this cutoff $(7,9)$. Because slow metabolizers typically compose one fourth of the general population of smokers, we oversampled this group to obtain equal numbers of slow and normal metabolizers. Participants and research staff involved with the PET scans were unaware of NMR. Of 35 eligible participants who scheduled a PET scan, 5 voluntarily withdrew before the PET scan, and 6 were withdrawn from the study because of noncompliance with study requirements (breath alcohol concentration reading $>0.01$ or exhaled $\mathrm{CO}>$ $15 \mathrm{ppm}$ at the PET scan) or a newly acquired MR imaging contraindication, leaving a final sample of 24 participants (12 slow metabolizers and 12 normal metabolizers). The 15-ppm cutoff for $\mathrm{CO}$ was used because overnight abstinence may not be sufficient to clear $\mathrm{CO}$ in smokers who have compromised pulmonary function. The average $\mathrm{CO}$ reading at session initiation was $8.2 \mathrm{ppm}$ (range: $4-15 \mathrm{ppm}$ ). A second $\mathrm{CO}$ reading, taken before scanning, averaged $3.5 \mathrm{ppm}$ (range: 2-7 ppm).

\section{Scanning Procedures}

Participants were instructed to cease smoking at 9:00 PM on the night before the scan visit. The visit started at 7:30 AM the next day, and the scan data acquisition was initiated at 3:00 PM. Thus, there was approximately $18 \mathrm{~h}$ of abstinence before scanning. After overnight nicotine abstinence, participants underwent PET brain imaging of $2-{ }^{18} \mathrm{~F}-\mathrm{FA}$ delivered by bolus plus infusion to shorten the duration of the PET imaging session, which is lengthened by the relatively slow receptor uptake of ${ }^{2-}{ }^{18} \mathrm{~F}-\mathrm{FA}(31)$. The time period of overnight abstinence was chosen because most smokers relapse in the first $24 \mathrm{~h}$ of an attempt to quit (12) and because our primary hypothesis concerned differences in receptor availability in early abstinence due to differences in rates of nicotine metabolism. At the start of the session, participants provided a urine sample for a drug screen, a breath alcohol sample ( $>0.01$ exclusionary), and a breath $\mathrm{CO}$ sample for biochemical confirmation of abstinence ( $\mathrm{CO}<15 \mathrm{ppm}$, or at least a $50 \%$ reduction from the intake session). During the PET scan, 2- ${ }^{18}$ F-FA (113.96-217.56 MBq [3.08-5.88 mCi]) was administered as a $50 \%$ bolus initially with additional $2-{ }^{18} \mathrm{~F}-\mathrm{FA}$ (115.07-222 MBq [3.11-6.0 mCi]) (50\%) administered as a continuous infusion over $8 \mathrm{~h}$. Participants completed $2 \mathrm{~h}$ of brain scanning begin- ning $6 \mathrm{~h}( \pm 30 \mathrm{~min})$ after injection to allow the radiotracer to achieve a steady state (31). PET scanning was performed on a Gemini TruFlight (TF) Big Bore PET/CT scanner (Philips Healthcare). A low-dose (120 kVp, $50 \mathrm{mAs}$ ) unenhanced $\mathrm{CT}$ scan of the head was performed before the emission acquisition for attenuation correction. PET images were reconstructed via an iterative line-of-response row-action maximumlikelihood algorithm using 2 iterations and 4 subsets and the sharp filter setting. Just before and immediately after the 2-h PET scan, participants completed the Brief Questionnaire on Smoking Urges (32), a validated measure of cravings to smoke.

To facilitate automatic generation of brain volumes of interest (VOIs), all participants received a T1-weighted anatomic scan on a Siemens MR scanner, with 3 participants on a 3-T Magnetom Sonata Syngo and 21 participants on a 1.5-T Magnetom Trio A Tim, acquired using magnetization-prepared $180^{\circ}$ radiofrequency pulses and rapid gradient-echo sampling. Subjects underwent MR scanning at a session different from the PET scan.

\section{Measurement of Unbound, Unmetabolized 2-18F-FA in Plasma}

Baseline venous blood samples were obtained before injection for assessment of $2-{ }^{18} \mathrm{~F}-\mathrm{FA}$ binding to plasma proteins, measurement of serum nicotine levels, and preparation of standards for the solid phase extraction process. The average nonmetabolized concentration of free $2-{ }^{18} \mathrm{~F}-\mathrm{FA}$ in plasma during the scan period was determined from an average of 5.8 blood samples (range, 3-6 samples; SD, \pm 0.7 ) for each participant from $5 \mathrm{~h}$ to $7.5 \mathrm{~h}$ after bolus injection. $2-{ }^{18} \mathrm{~F}-\mathrm{FA}$ binding to plasma proteins was evaluated by ultrafiltration using YM-10 filtration devices (Millipore Corp.). Additional venous blood samples ( $\sim 3 \mathrm{~mL}$ ) were drawn at predetermined intervals during the infusion period for measurement of unbound, nonmetabolized $2-{ }^{18} \mathrm{~F}-\mathrm{FA}$. Samples were centrifuged at $4,000 \times \mathrm{g}$ for $15 \mathrm{~min}$, and plasma radioactivity was measured using an automated $\gamma$ counter. Radioactivity attributable to nonmetabolized $2-{ }^{18} \mathrm{~F}-\mathrm{FA}$ was determined using solid phase extraction with Clean Screen extraction columns $(200 \mathrm{mg} / 10 \mathrm{~mL}$; United Chemical Technologies, Inc.) (33).

\section{Data Analysis}

PET Analysis Including Automatic Generation of Brain VOIs and Partial Volume Correction. To standardize the PET imaging acquisition times after radiotracer administration across all subjects, we used only the 90 min of PET scanning that was contemporaneous for all participants-6.25-7.75 h after bolus injection-using six 15-min time bins (mean midpoint of scans was $7.0 \pm 0.1 \mathrm{~h}$ after bolus injection). Each participant's PET image and T1-weighted MR scan were coregistered, and brain VOIs were automatically defined using the T1-weighted MR imaging parcellation PNEURO tool in PMOD software (PMOD Technologies Ltd., version 3.5). Mean regional time-activity curves were output by PMOD software with partial volume correction based on a variant of the Rousset correction method, whereby $15 \%$ of the pixels in the inner VOI were used for calculating the VOI average. Average activity concentrations for the 90-min period were decay-corrected to the time of bolus injection for use in subsequent calculations.

Calculation of Total Distribution Volume $\left(V_{T} / f_{P}\right) . \mathrm{V}_{\mathrm{T}} / \mathrm{f}_{\mathrm{P}}$ was calculated as the ratio of average, partial volume-corrected $2-{ }^{18} \mathrm{~F}-\mathrm{FA}$ concentration in brain to unbound, nonmetabolized $2-{ }^{18} \mathrm{~F}-\mathrm{FA}$ concentration in plasma (31).

Generation of Mean PET Images for Participant Cohorts. Using each participant's calculated distribution volume $\left(\mathrm{V}_{\mathrm{T}} / \mathrm{f}_{\mathrm{P}}\right)$, mean images of participant $\mathrm{V}_{\mathrm{T}} / \mathrm{f}_{\mathrm{P}} \mathrm{S}$ were created, with both PET image and plasma activity concentrations decay-corrected to the time of $2{ }^{18} \mathrm{~F}$-FA bolus injection. All participants' $V_{T} / f_{P}$ images were spatially normalized to the same template, and the resulting $\mathrm{V}_{\mathrm{T}} / \mathrm{f}_{\mathrm{P}}$ images were averaged for participants 
with normal hepatic nicotine metabolism $(n=12)$ and for participants with slower rates of hepatic nicotine metabolism $(n=12)$.

Descriptive statistics were generated for demographic and smoking variables, with differences between NMR groups being tested using $t$ tests and $\chi^{2}$ tests. Group differences in $\mathrm{V}_{\mathrm{T}} / \mathrm{f}_{\mathrm{P}}$ in the a priori VOIs were estimated by ANOVA, including age, sex, and average cigarettes per day as covariates; nonsignificant covariates were allowed to drop from the models at a $P$ value of less than 0.1 . Associations between $\mathrm{V}_{\mathrm{T}} / \mathrm{f}_{\mathrm{P}}$ and craving were tested using regression models including mean QSU total score as the outcome and $\mathrm{V}_{\mathrm{T}} / \mathrm{f}_{\mathrm{P}}$ in the a priori regions as the primary predictor. $\alpha$ was adjusted on the basis of 4 VOIs with an average correlation of 0.95 , resulting in an adjusted $P$ value of 0.047 . Twenty-four smokers provided $80 \%$ power to detect an NMR group-effect size of $1.2(34)$.

\section{RESULTS}

Demographic statistics for the study sample are summarized in Table 1. There were no significant differences in age, sex, race, cigarettes per day, or Fagerström Test for Nicotine Dependence score between the NMR groups $(P>0.05)$.

Receptor availability was significantly greater (as measured by $2-{ }^{18} \mathrm{~F}-\mathrm{FA} \mathrm{V} \mathrm{V}_{\mathrm{T}} / \mathrm{f}_{\mathrm{P}}$ ) in normal metabolizers than it was in slow metabolizers in the thalamus bilaterally, where the concentration of nAChRs is highest $\left(F=4.92_{1}, P=0.037\right)$. Significant associations were not observed in other tested regions: whole brain, temporal lobes, and frontal lobes; however, trends in all regions were observed (Figs. 1 and 2).

There were no significant associations between $V_{\mathrm{T}} / \mathrm{f}_{\mathrm{P}}$ in the 4 VOIs and self-reported urges to smoke. Urges to smoke did not differ between slow and normal metabolizers before scanning; however, the groups differed with respect to changes in urges before and after scanning, with slow metabolizers exhibiting a decrease (mean change in slow metabolizers, $-8.1 ; \mathrm{SE}=2.9$ ) and normal metabolizers showing a slight increase (mean change of $+1.8 ; \mathrm{SE}=2.2$ ).

TABLE 1

Demographic and Smoking-Related Variables at Baseline

\begin{tabular}{|c|c|c|}
\hline Group & Normal metabolizers $(n=12)$ & Slow metabolizers $(n=12)$ \\
\hline \multicolumn{3}{|l|}{ Race } \\
\hline African American & 8 & 9 \\
\hline Caucasian & 4 & 3 \\
\hline \multicolumn{3}{|l|}{ Age $(y)$} \\
\hline Mean \pm SD & $48.7 \pm 9.2$ & $45.5 \pm 11.6$ \\
\hline Range & $35-64$ & $23-62$ \\
\hline \multicolumn{3}{|l|}{$\operatorname{Sex}(n)$} \\
\hline Male & $5(42 \%)$ & $6(50 \%)$ \\
\hline Female & $7(58 \%)$ & $6(50 \%)$ \\
\hline \multicolumn{3}{|l|}{ Cigarettes per day $(n)$} \\
\hline Mean \pm SD & $16.9 \pm 8.4$ & $17.0 \pm 3.4$ \\
\hline Range & $10-40$ & $11-20$ \\
\hline \multicolumn{3}{|l|}{ FTND } \\
\hline Mean \pm SD & $5.9 \pm 2.2$ & $5.4 \pm 1.78$ \\
\hline Range & $2-9$ & $2-8$ \\
\hline \multicolumn{3}{|l|}{$\mathrm{CO}$ at intake (ppm) } \\
\hline Mean \pm SD & $21.2 \pm 5.8$ & $25.0 \pm 7.7$ \\
\hline Range & $12-29$ & $12-35$ \\
\hline \multicolumn{3}{|c|}{ Plasma cotinine at intake $(\mathrm{ng} / \mathrm{mL})$} \\
\hline Mean \pm SD & $219.7 \pm 64.1$ & $323.9 \pm 143.9$ \\
\hline Range & 119.8-329.2 & $154.1-604.5$ \\
\hline \multicolumn{3}{|c|}{ Plasma 3-hydroxycotinine at intake (ng/mL) } \\
\hline Mean \pm SD & $104.6 \pm 50.8$ & $51.8 \pm 27.8$ \\
\hline Range & $31.9-195.0$ & $18.5-100.2$ \\
\hline \multicolumn{3}{|l|}{ Plasma NMR at intake } \\
\hline Mean \pm SD & $0.467 \pm 0.192$ & $0.170 \pm 0.059$ \\
\hline Range & $0.266-0.908$ & $0.08-0.259$ \\
\hline
\end{tabular}

FTND = Fagerström Test for Nicotine Dependence.

No significant differences were present between normal and slow metabolizers $(P=0.67,0.47,0.7,0.98,0.62$, and 0.18 for race, mean age, sex, cigarettes per day, FTND, and CO, respectively). Serum nicotine values are not included because time between last cigarette and sampling was not standardized. 


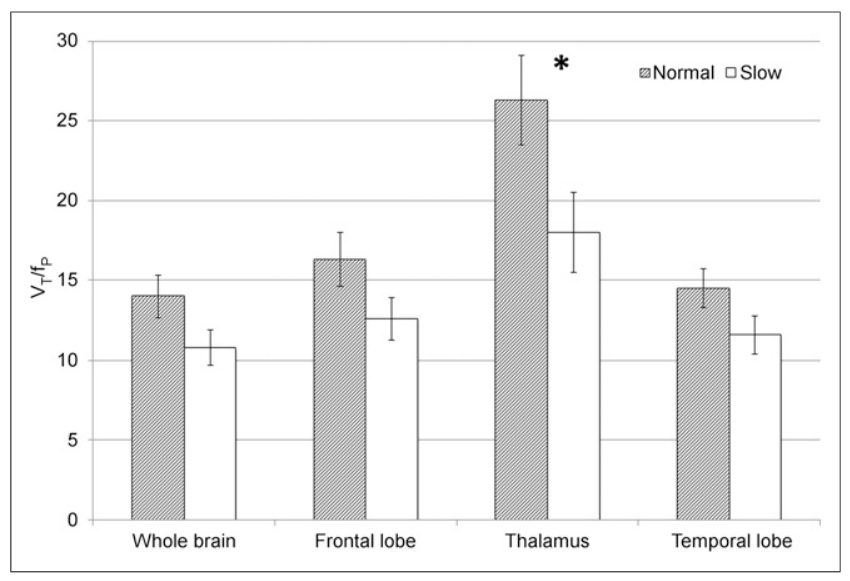

FIGURE 1. $2-{ }^{18} \mathrm{~F}-\mathrm{FA}$ partial volume-corrected $\mathrm{V}_{T} / \mathrm{f}_{\mathrm{P}}$ by region and NMR group: Smokers with slower nicotine metabolism (NMR $<0.26$ ) demonstrated less $\mathrm{V}_{T} / \mathrm{f}_{\mathrm{P}}$ in brain than those with normal metabolism, including in thalamus $(P=0.037)$, region of greatest $n A C h R$ density within CNS. This relationship persisted and approached significance when $\mathrm{V}_{\mathrm{T}} / \mathrm{f}_{\mathrm{P}}$ of slow (bottom quartile) and normal NMR groups were compared for entire brain $(P=0.07)$. $P$ values were calculated using 1-way ANOVA. Error bars show SEM. For whole brain, frontal lobe, thalamus, and temporal lobe, $P=0.07,0.1,0.04$, and 0.1 , respectively. ${ }^{*} P<0.05$

\section{DISCUSSION}

These data suggest that slow metabolizers of nicotine exhibit reduced nAChR availability in the thalamus after $18 \mathrm{~h}$ of abstinence from smoking, compared with normal nicotine metabolizers. Individual variation in hepatic metabolism increases the nicotine half-life in plasma from approximately 2 to $4 \mathrm{~h}$ (35-37). In addition, nicotine levels in the brain can persist beyond nicotine plasma half-life $(22,24)$. Therefore, differences in thalamic nAChR availability observed between slow and normal metabolizers may reflect differences in nicotine binding to nAChRs that result from differences in elimination kinetics. Nonetheless, other possibilities, such as differences in $\mathrm{nAChR}$ expression or binding, should be considered. For example, in nonhuman primates at baseline before nicotine exposure, $2-{ }^{18} \mathrm{~F}-\mathrm{FA} \mathrm{V}_{\mathrm{T}} / \mathrm{f}_{\mathrm{P}}$ binding is believed to be reflective of $\mathrm{nAChR}$ expression because the radiotracer does not compete with nicotine as it does in smokers (38). However, definitive measurement of $\mathrm{nAChR}$ protein expression requires use of histopathologic techniques $(14,39)$. Binding of the radiotracer with plasma proteins before crossing the bloodbrain barrier and interacting with nAChRs could occur, but the established bolus-plus-infusion technique used should account for such an interaction (31). Four of the 24 smokers had persistent nicotine in their blood after overnight abstinence: 3 slow metabolizers and 1 normal metabolizer. These values measured less than $5 \mathrm{ng} / \mathrm{mL}$. Although such levels could interfere with radiotracer binding, we intentionally timed the study so that nicotine might persist in the blood (and brain) of slow metabolizers. Not surprisingly, because of its participation in numerous neuronal circuits, the thalamus has been implicated in nicotine dependence by both functional MR imaging and PET studies $(40,41)$. Although in the present study significance was detected only in the thalamus, the region of greatest $\mathrm{nAChR}$ availability, the trend suggests a whole-brain phenomenon. It is possible, however, that overnight abstinence was not sufficient to reveal other involved neuroanatomical locations.
Although validation of these preliminary findings is necessary, the results suggest that normal metabolizers of nicotine, who have faster rates of nicotine elimination, also exhibit greater $\mathrm{nAChR}$ availability during the first day after an attempt to quit. Other data show that smokers with a higher specific-binding volume of distribution (a measure of $\mathrm{nAChR}$ availability) are more likely to relapse after an attempt to quit (42). Thus, future research could examine whether increased $\mathrm{nAChR}$ availability in normal metabolizers mediates the increased likelihood of relapse on nicotine patch or the greater efficacy of varenicline in this group (10).

In addition, although nAChR expression and availability are dynamic and influenced by age, sex, and hormones, including estrogen and progesterone (43), age and sex were not associated with nAChR availability in our sample. The relatively small sample size is another limitation; however, the relationship between NMR and nAChR availability was consistent with the a priori hypothesis. Prior $2-{ }^{18}$ F-FA-PET imaging studies have used abstinence periods of at least $36-48 \mathrm{~h}$ to ensure complete depletion of nicotine. Future studies in slow and normal metabolizers that include a second scan at least $1 \mathrm{wk}$ later would be valuable to explore whether differences in availability can be attributed to long-term occupancy or upregulation.

It is also important to note that the nAChR, a nonselective cation channel, may exist in multiple conformational states (44). Binding of an agonist such as nicotine may stabilize the receptor

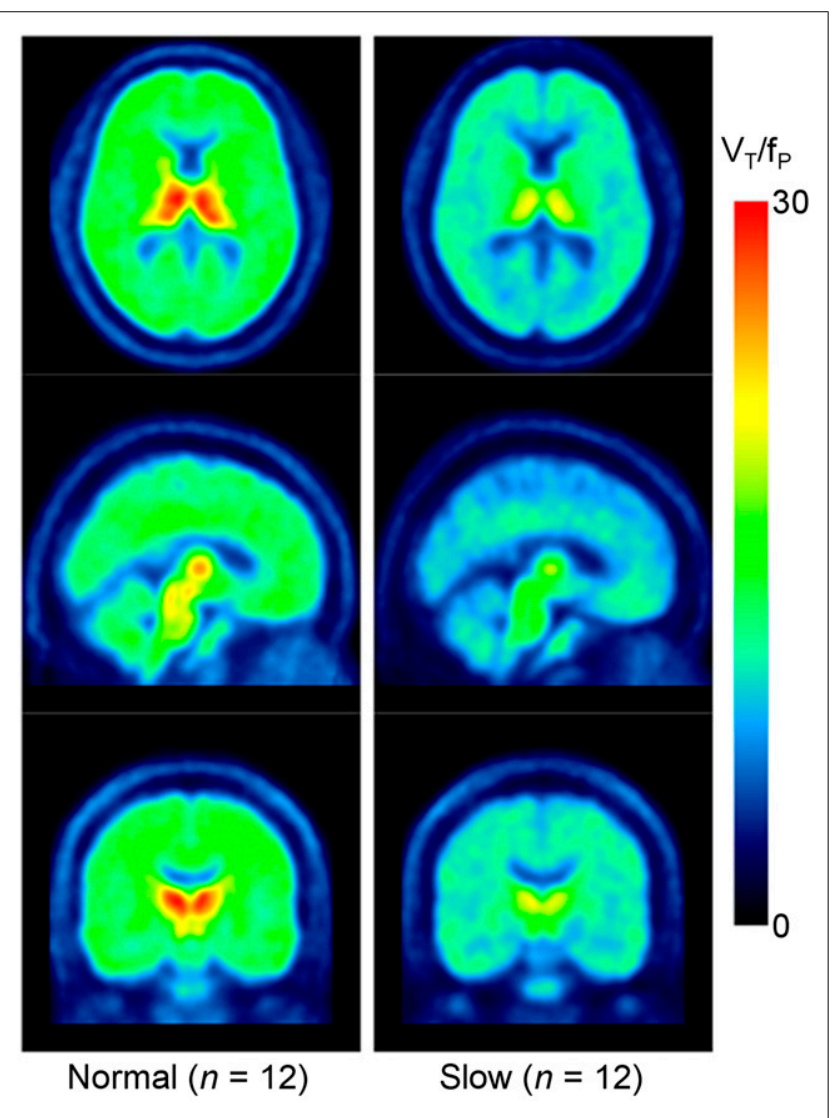

FIGURE 2. Mean $2{ }^{-18} \mathrm{~F}-\mathrm{FA} \mathrm{V}_{\mathrm{T}} / \mathrm{f}_{\mathrm{P}}$ PET images demonstrating lower $2{ }^{-18} \mathrm{~F}-\mathrm{FA}$ binding in subgroup with slower hepatic metabolism of nicotine. Mean PET images for normal metabolizers (left) and those with slower rates of hepatic nicotine metabolism (right) were spatially normalized to same template. 


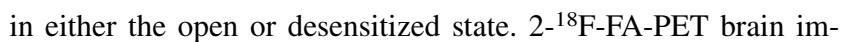
aging cannot determine the current conformational state of unavailable receptors. The timing of $\mathrm{nAChR}$ densensitization (decreased response to nicotine exposure) has been studied in cell culture (45), but in vivo molecular imaging methods lack the temporal resolution to distinguish between an nAChR that is densensitized to nicotine and one that is not. Despite this shortcoming, $2{ }^{18}$ F-FA-PET brain imaging has established validity for detecting differences in tobacco exposure and for predicting smoking cessation $(19,23,26,46)$. Finally, it should be noted that although increases in cravings to smoke among normal (vs. slow) metabolizers were noted, consistent with faster clearance of nicotine, levels of craving or changes in craving did not correlate with nAChR availability.

\section{CONCLUSION}

These results suggest that individual differences in the rates of metabolism of nicotine, based on the NMR, are associated with nAChR availability in smokers shortly after an attempt to quit. Manipulation of nicotine hepatic metabolism could be valuable in improving smoking cessation rates $(47,48)$. This study further reinforces prior evidence that PET imaging of the $\alpha 4 \beta 2 * \mathrm{nAChR}$ subtype represents a promising biomarker of nicotine exposure and possibly smoking cessation success. In addition, it raises the underappreciated issue of how psychoactive drug metabolism influences neuronal receptor expression and availability.

\section{DISCLOSURE}

The costs of publication of this article were defrayed in part by the payment of page charges. Therefore, and solely to indicate this fact, this article is hereby marked "advertisement" in accordance with 18 USC section 1734. This work was supported by a grant from the Pharmacogenetics Research Network (PNAT, U01DA20830), the Abramson Cancer Center at the University of Pennsylvania, the Institute for Translational Medicine and Therapeutics of the Perelman School of Medicine at the University of Pennsylvania (NIH), a McCabe Pilot Award (University of Pennsylvania), and the Commonwealth of Pennsylvania (the Pennsylvania Department of Health disclaims responsibility for analyses, interpretations, or conclusions). Additional support was provided by Pfizer, the National Center for Research Resources, and the National Center for Advancing Translational Sciences, National Institutes of Health (UL1TR000003). Arthur Brody is supported by grants from the National Institute on Drug Abuse (R01 DA20872), the Department of Veterans Affairs Office of Research and Development (CSR\&D Merit Review Award I01 CX000412), and the Tobacco-Related Disease Research Program (23XT-0002). The content is solely the responsibility of the authors and does not necessarily represent the official views of the NIH. No other potential conflict of interest relevant to this article was reported.

\section{REFERENCES}

1. WHO report on the global tobacco epidemic, 2011: warning about the dangers of tobacco. World Health Organization website. http://www.who.int/tobacco/ global_report/2011/en/. Published 2011. Accessed August 27, 2015.

2. Centers for Disease Control and Prevention. Current cigarette smoking among adults: United States, 2011. Morb Mortal Wkly Rep. 2012;61:889-894.

3. Centers for Disease Control and Prevention. Annual smoking-attributable mortality, years of potential life lost, and economic costs: United States-19951999. Morb Mortal Wkly Rep. 2002;14:300-303.
4. 2008 PHS Guideline Update Panel, Liaisons, and Staff. Treating tobacco use and dependence: 2008 update U.S. Public Health Service Clinical Practice Guideline executive summary. Respir Care. 2008;53:1217-1222.

5. Benowitz NL, Pomerleau OF, Pomerleau CS, Jacob P III. Nicotine metabolite ratio as a predictor of cigarette consumption. Nicotine Tob Res. 2003;5:621-624.

6. Dempsey D, Tutka P, Jacob P III, et al. Nicotine metabolite ratio as an index of cytochrome P450 2A6 metabolic activity. Clin Pharmacol Ther. 2004;76:64-72.

7. Lerman C, Tyndale R, Patterson F, et al. Nicotine metabolite ratio predicts efficacy of transdermal nicotine for smoking cessation. Clin Pharmacol Ther. 2006;79:600-608.

8. Ray R, Tyndale RF, Lerman C. Nicotine dependence pharmacogenetics: role of genetic variation in nicotine-metabolizing enzymes. J Neurogenet. 2009;23:252-261.

9. Schnoll RA, Patterson F, Wileyto EP, Tyndale RF, Benowitz N, Lerman C. Nicotine metabolic rate predicts successful smoking cessation with transdermal nicotine: a validation study. Pharmacol Biochem Behav. 2009;92:6-11.

10. Lerman C, Schnoll RA, Hawk LW Jr, et al. Use of the nicotine metabolite ratio as a genetically informed biomarker of response to nicotine patch or varenicline for smoking cessation: a randomised, double-blind placebo-controlled trial. Lancet Respir Med. 2015;3:131-138.

11. Vaz LR, Coleman T, Cooper S, Aveyard P, Leonardi-Bee J. The nicotine metabolite ratio in pregnancy measured by trans- 3 '-hydroxycotinine to cotinine ratio: characteristics and relationship with smoking cessation. Nicotine Tob Res. January 14, 2015 [Epub ahead of print].

12. Piasecki TM. Relapse to smoking. Clin Psychol Rev. 2006;26:196-215.

13. Westman EC, Behm FM, Simel DL, Rose JE. Smoking behavior on the first day of a quit attempt predicts long-term abstinence. Arch Intern Med. 1997;157:335340

14. Benwell ME, Balfour DJ, Anderson JM. Evidence that tobacco smoking increases the density of $(-)-\left[{ }^{3} \mathrm{H}\right]$ nicotine binding sites in human brain. J Neurochem. 1988;50:1243-1247.

15. Breese CR, Marks MJ, Logel J, et al. Effect of smoking history on $\left[{ }^{3} \mathrm{H}\right]$ nicotine binding in human postmortem brain. J Pharmacol Exp Ther. 1997;282:7-13.

16. Flores CM, Rogers SW, Pabreza LA, Wolfe BB, Kellar KJ. A subtype of nicotinic cholinergic receptor in rat brain is composed of alpha 4 and beta 2 subunits and is up-regulated by chronic nicotine treatment. Mol Pharmacol. 1992;41:31-37.

17. Perry DC, Davila-Garcia MI, Stockmeier CA, Kellar KJ. Increased nicotinic receptors in brains from smokers: membrane binding and autoradiography studies. J Pharmacol Exp Ther. 1999;289:1545-1552.

18. Whiting PJ, Lindstrom JM. Characterization of bovine and human neuronal nicotinic acetylcholine receptors using monoclonal antibodies. J Neurosci. 1988;8: 3395-3404.

19. Brody AL, Mukhin AG, La Charite J, et al. Up-regulation of nicotinic acetylcholine receptors in menthol cigarette smokers. Int $J$ Neuropsychopharmacol. 2013;16:957-966.

20. Ding YS, Molina PE, Fowler JS, et al. Comparative studies of epibatidine derivatives $\left[{ }^{18} \mathrm{~F}\right] \mathrm{NFEP}$ and $\left[{ }^{18} \mathrm{~F}\right] \mathrm{N}$-methyl-NFEP: kinetics, nicotine effect, and toxicity. Nucl Med Biol. 1999;26:139-148.

21. Gallezot JD, Bottlaender M, Gregoire MC, et al. In vivo imaging of human cerebral nicotinic acetylcholine receptors with $2-{ }^{18} \mathrm{~F}$-fluoro-A-85380 and PET. J Nucl Med. 2005;46:240-247.

22. Staley JK, Krishnan-Sarin S, Cosgrove KP, et al. Human tobacco smokers in early abstinence have higher levels of beta $2 *$ nicotinic acetylcholine receptors than nonsmokers. J Neurosci. 2006;26:8707-8714.

23. Brody AL, Mukhin AG, Shulenberger S, et al. Treatment for tobacco dependence: effect on brain nicotinic acetylcholine receptor density. Neuropsychopharmacology. 2013;38:1548-1556.

24. Cosgrove KP, Batis J, Bois F, et al. Beta2-nicotinic acetylcholine receptor availability during acute and prolonged abstinence from tobacco smoking. Arch Gen Psychiatry. 2009;66:666-676.

25. Brody AL, Mandelkern MA, London ED, et al. Effect of secondhand smoke on occupancy of nicotinic acetylcholine receptors in brain. Arch Gen Psychiatry. 2011;68:953-960.

26. Brody AL, Mandelkern MA, London ED, et al. Cigarette smoking saturates brain alpha 4 beta 2 nicotinic acetylcholine receptors. Arch Gen Psychiatry. 2006;63:907915.

27. Lotfipour S, Mandelkern M, Alvarez-Estrada M, Brody AL. A single administration of low-dose varenicline saturates alpha4beta $2 *$ nicotinic acetylcholine receptors in the human brain. Neuropsychopharmacology. 2012;37:1738-1748.

28. Lotfipour S, Mandelkern M, Brody AL. Quantitative molecular imaging of neuronal nicotinic acetylcholine receptors in the human brain with A-85380 radiotracers. Curr Med Imaging Rev. 2011;7:107-112.

29. Brody AL, Mandelkern MA, Costello MR, et al. Brain nicotinic acetylcholine receptor occupancy: effect of smoking a denicotinized cigarette. Int J Neuropsychopharmacol. 2009;12:305-316. 
30. Sheehan DV, Lecrubier Y, Sheehan KH, et al. The Mini-International Neuropsychiatric Interview (M.I.N.I.): the development and validation of a structured diagnostic psychiatric interview for DSM-IV and ICD-10. J Clin Psychiatry. 1998; 59(suppl 20):22-33.

31. Kimes AS, Chefer SI, Matochik JA, et al. Quantification of nicotinic acetylcholine receptors in the human brain with PET: bolus plus infusion administration of 2-[ $\left.{ }^{18} \mathrm{~F}\right] \mathrm{F}-\mathrm{A} 85380$. Neuroimage. 2008;39:717-727.

32. Cox LS, Tiffany ST, Christen AG. Evaluation of the brief questionnaire of smoking urges (QSU-brief) in laboratory and clinical settings. Nicotine Tob Res. 2001;3:7-16

33. Shumway DA, Pavlova OA, Mukhin AG. A simplified method for the measurement of nonmetabolized 2-[ $\left.{ }^{18} \mathrm{~F}\right] \mathrm{F}-\mathrm{A}-85380$ in blood plasma using solid-phase extraction. Nucl Med Biol. 2007;34:221-228.

34. Faul F, Erdfelder E, Lang AG, Buchner A. G*Power 3: a flexible statistical power analysis program for the social, behavioral, and biomedical sciences. Behav Res Methods. 2007;39:175-191.

35. Benowitz NL, Perez-Stable EJ, Herrera B, Jacob P III. Slower metabolism and reduced intake of nicotine from cigarette smoking in Chinese-Americans. J Natl Cancer Inst. 2002;94:108-115.

36. Benowitz NL, Swan GE, Jacob P III, Lessov-Schlaggar CN, Tyndale RF. CYP2A6 genotype and the metabolism and disposition kinetics of nicotine. Clin Pharmacol Ther. 2006;80:457-467.

37. Levi M, Dempsey DA, Benowitz NL, Sheiner LB. Population pharmacokinetics of nicotine and its metabolites I. Model development. J Pharmacokinet Pharmacodyn. 2007;34:5-21.

38. Le Foll B, Chefer SI, Kimes AS, et al. Baseline expression of alpha4beta2* nicotinic acetylcholine receptors predicts motivation to self-administer nicotine. Biol Psychiatry. 2009;65:714-716.
39. Marks MJ, McClure-Begley TD, Whiteaker P, et al. Increased nicotinic acetylcholine receptor protein underlies chronic nicotine-induced up-regulation of nicotinic agonist binding sites in mouse brain. J Pharmacol Exp Ther. 2011;337: 187-200.

40. Menossi HS, Goudriaan AE, de Azevedo-Marques Perico C, et al. Neural bases of pharmacological treatment of nicotine dependence: insights from functional brain imaging-a systematic review. CNS Drugs. 2013;27:921-941.

41. Sharma A, Brody AL. In vivo brain imaging of human exposure to nicotine and tobacco. Handb Exp Pharmcol. 2009;(192):145-171.

42. Brody AL, Mukhin AG, Mamoun MS, et al. Brain nicotinic acetylcholine receptor availability and response to smoking cessation treatment: a randomized trial. JAMA Psychiatry. 2014;71:797-805.

43. Cosgrove KP, Esterlis I, McKee SA, et al. Sex differences in availability of $\beta 2 *$-nicotinic acetylcholine receptors in recently abstinent tobacco smokers. Arch Gen Psychiatry. 2012;69:418-427.

44. Cooper JR, Bloom FE, Roth RH. The Biochemical Basis of Neuropharmacology. New York, New York: Oxford University Press; 2003:151-179.

45. Campling BG, Kuryatov A, Lindstrom J. Acute activation, desensitization and smoldering activation of human acetylcholine receptors. PLoS One. 2013;8: e79653.

46. Mukhin AG, Kimes AS, Chefer SI, et al. Greater nicotinic acetylcholine receptor density in smokers than in nonsmokers: a PET study with $2-{ }^{18} \mathrm{~F}-\mathrm{FA}-85380 . J$ Nucl Med. 2008;49:1628-1635.

47. Sellers EM, Ramamoorthy Y, Zeman MV, Djordjevic MV, Tyndale RF. The effect of methoxsalen on nicotine and 4-(methylnitrosamino)-1-(3-pyridyl)-1butanone (NNK) metabolism in vivo. Nicotine Tob Res. 2003;5:891-899.

48. Siu EC, Tyndale RF. Selegiline is a mechanism-based inactivator of CYP2A6 inhibiting nicotine metabolism in humans and mice. J Pharmacol Exp Ther. 2008;324:992-999. 